\title{
Analysis of Structure and Tectonics Based on Architecture and Design
}

\author{
${ }^{1}$ Rustem F. Mirhasanov, ${ }^{2}$ Albina R. Gatina, ${ }^{3}$ Elmira G. Akhmetshina, ${ }^{4}$ Aigerim S. Turgunbaeva \\ ${ }^{1}$ Gymnasium No.126, Kazan, Tatarstan, Russia, \\ ${ }^{2,3}$ Kazan Federal University, Kazan, Tatarstan, Russia, \\ ${ }^{4}$ Diplomatic Academy MFA KR named after K.Dikambaev, Kyrgyz Republic \\ Email: albina-gatina@yandex.ru
}

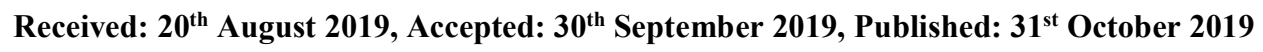

\begin{abstract}
The article describes the problem of attention increase to descriptive analysis of world design products in educational and industrial, in creative and design practice. The study revealed the rules according to which the products of designer's creative activity are formed. To address the issues of studying design and tectonics using the example of compositional analysis of design art heritage samples, which have become classic examples of international design, they provide the rationale for the terminological apparatus for its subsequent inclusion in the training system for future designers.

The compositional design of architectural structures, which were the objects of imitation and inspiration for modern masters, demonstrates the visual plasticity of the wall framework movement, pronounced in the system of arcbutans and buttresses of Gothic temples, in courvatures and entasis of the ancient Greek architecture, and the tectonics of the entire structure in general.

The article deals with the tectonics of furniture designs made of natural materials in the creative work of the Finnish designer Alvar Aalto. The master's works show the combination of democracy with elegance, naturalness and rationalism. The maximum prevalence of form over content is fully observed in international architecture and design, but A. Aalto's projects demonstrate the harmony between the traditions of folk architecture and the novelty of avantgarde techniques, the national traditions of architecture with flexibility and freedom of volumetric and spatial compositions.
\end{abstract}

Keywords

Form, Content, Tectonics, Load-Bearing Structure, Buttress, Arcbutan, Formal Sphere, International Design, Rock Garden.

\section{Introduction}

The analysis of "construction", "tectonics" and "form and content" in the works of world classics is, in our opinion, an interesting and important area of study for theoretical and practical research in educational and creative activities within the field of design. Practitioners, the theorists of art construction (the term of the USSR), the design students are interested in understanding the existing connection and common interpretation of the terms "form" and "design" in various forms of art, the proximity of their "reading" in painting that is flat on the graphic surface, spatial and temporal perception of architecture and rapidly developing Russian art of design [1].

Both in the field of design and in the professional training of design students, there is the problem of discrepancies in deciphering the existing terminological apparatus in different types of fine art, the problem of assessment the significance of certain products of master designers who have contributed to the modern development of design, as well as rapidly developing trends of world art [2]. To solve these problems, which will only multiply with the advent of all new technical means, scientific discoveries, on the basis of which unprecedented trends and types of artistic design activity will be based, a properly organized analytical system of training students in design, as well as the model of educational and creative activities conducive to the education of a future designer creative personality are necessary [3]. The term "design" was briefly defined in 1969 at the Congress of the International Council of Design Organizations: "The term design refers to creative activity whose purpose is to determine the formal qualities of objects produced by industry." These qualities of the form apply not only to the appearance, but mainly to the structural and functional relationships that turn the system in holistic unity from the point of view of both the manufacturer and the consumer" [4; p. 30].

Thus, the very definition of the term design implies creative activity to create not only an external aesthetic appearance, but also a holistic system (the main law of the composition of integrity and indivisibility) of functional and structural ties [5]. The object of architectural and design solution (except for graphic design products and architectural graphic fantasies) of a spatial nature is associated with the natural law of universal gravitation, and structural elements bearing the weight of the floors and expressed in the external shape of an object. 


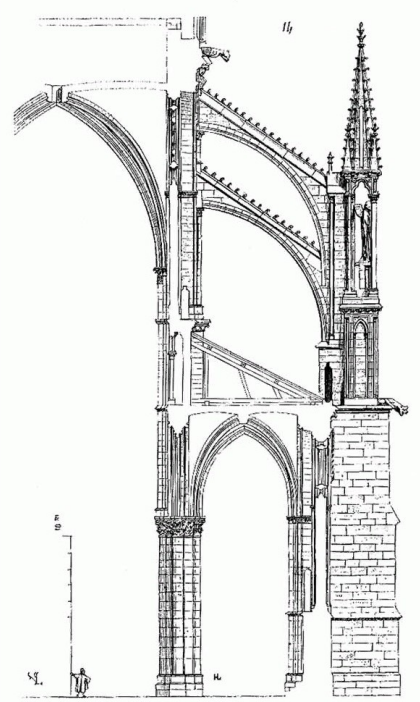

Figure 1: Openwork Wall of the Gothic Cathedral

Openwork wall of the Gothic cathedral, due to the huge numerous windows, would be perceived visually "not sufficiently convincingly strong" if it weren't for the solid and long "spider legs" of buttresses and arcbutans, which convince of the strength of the upward-looking structure, reminiscent of a space rocket and openwork metal trusses that fix it at the spaceport.(Fig. 1)

The compositional design in a Gothic temple is tectonics - the visual plastics of a load-bearing wall frame movement, load distribution through the keystone, gradual "damping", transfer of load distribution from inside to outside from the walls in the horizontal direction through inclined arcbutans to buttresses. The same design, not of a real, physical, but of a visual nature, exists in a well-painted canvas, which was competently "built" from the perspective of composition architectonics.

\section{Methods}

Based on the foregoing, there is an important problem of understanding students and future designers in design art practice and teaching concerning isolation and the ability to analyze the union of compositional form and content in the newly created designer art form.

The study uses the methods of comparative analysis of the art forms of architectural objects and the compositional design of furniture, the methods of historical and architectural research (complex and systemic).

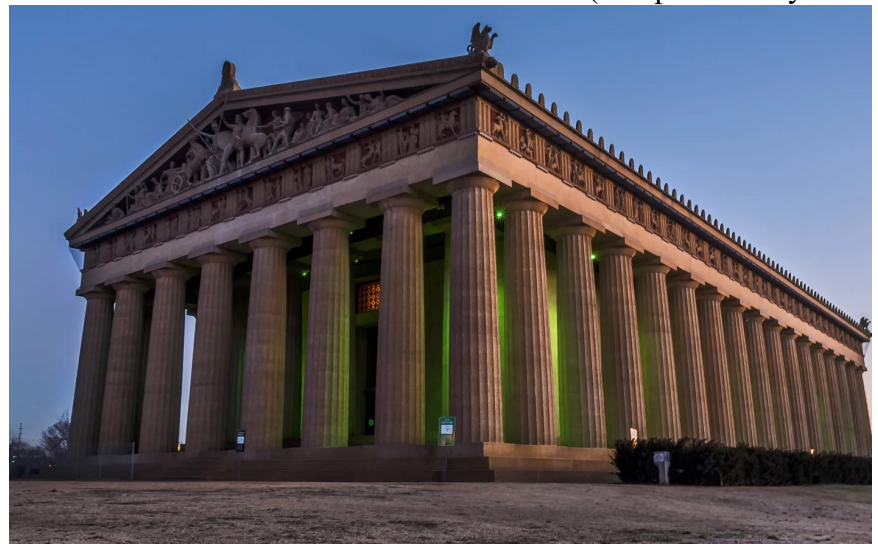

Figure 2: Classical Architectural Art - The Parthenon

The importance of tectonics was realized by ancient Greek architects: (Fig. 2)

1. Curvature - the curvature of contour lines;

2. The diameter increase of the corner columns of the Parthenon

3. The entasis of the columns as an expression of tension image, the importance of weight bearing rack-and-beam structure.

Let us give an example of classical architectural art form analysis with its substantial and compositional part based on an ancient Greek temple. In ancient Greek temples, sculpture was located between structural elements, for example, in 
gables that did not carry the main load. I.e. the composite part (constructive tectonic), the part of the unified artificial art form - the temple - was the load-bearing architectural elements, and the sculptural plastic had the "decorating" function of the content - the "story". The sculptural group in the eastern part of the temple usually told about the gods to whom the temple was dedicated, and in the western part heroes were presented who interacted with celestials.

This analysis allows us to draw an analogy with the forms and design features of the designer's creative activity products. Carrying out the process of objective reflection on the results of this activity, students can deeply understand the ongoing projects of educational creative activity.

The training of future designers, technical and technological literacy in the implementation of practical work consists in a comprehensive study and selection of artistic means and materials and is implemented by the example of analogue analysis from the world heritage of design masterpieces [6]. Let's try to consider the analysis of furniture samples that have become the classics of world design.

\section{Results and Discussion}

Alvar Aalto is a famous architect and designer of Finland, one of the main representatives of Scandinavian design and the founder of international design. He was born in the small Finnish settlement of Kuortana. In 1916-1921 he studied at the Faculty of Architecture at the Helsinki Polytechnic Institute. The 20-30-ies of the XX-th century is the beginning of the active creative activity of the Finnish designer Alvar Aalto.

Bent tree, multilayer plywood is a natural material that the designer uses to symbolize the industriousness of the Finnish people and their newly acquired state independence in the 1920-ies.

The stool Model 60 is the ideal of design simplicity, surprisingly durable, characterized by democratic elegance and the "open" natural beauty of the material, emphasized only by transparent varnish.

Mutual combinatorics of individual pieces of the furniture Model 60 is so well-formulated that they easily stack in a compact vertical stack. This design of the stool was developed by Aalto during 1930-1933 and even after almost 100 years it is demanded among by population in Ikea stores. Model 60 has a very interesting figurative series of natural analogues: from a spider, to a flower with wilted petals and the sun. (Fig. 3)

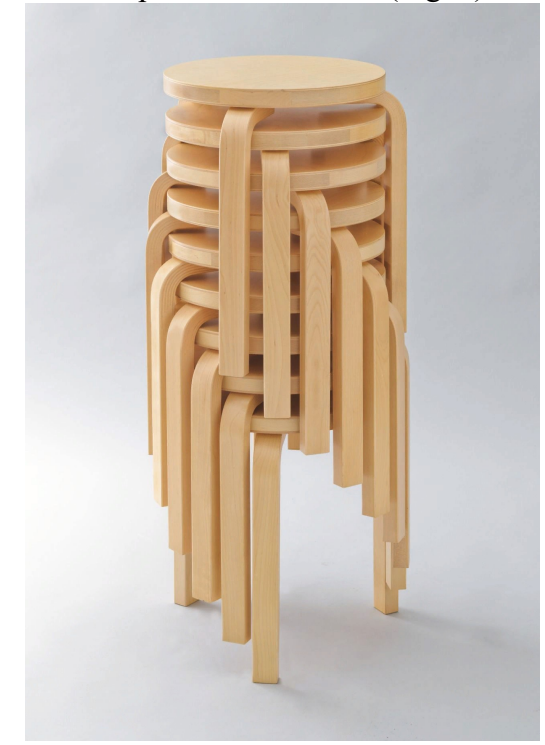

Figure 3: The Design of the Stool

At his house in Helsinki (1936), Alvar Aalto refracts, uses in his work the natural features of Finland - timber reserves, the motives of a traditional North European, and specifically, Finnish dwelling. The ideas of democracy, rationalism of architects - functionalists are strong in his art. 


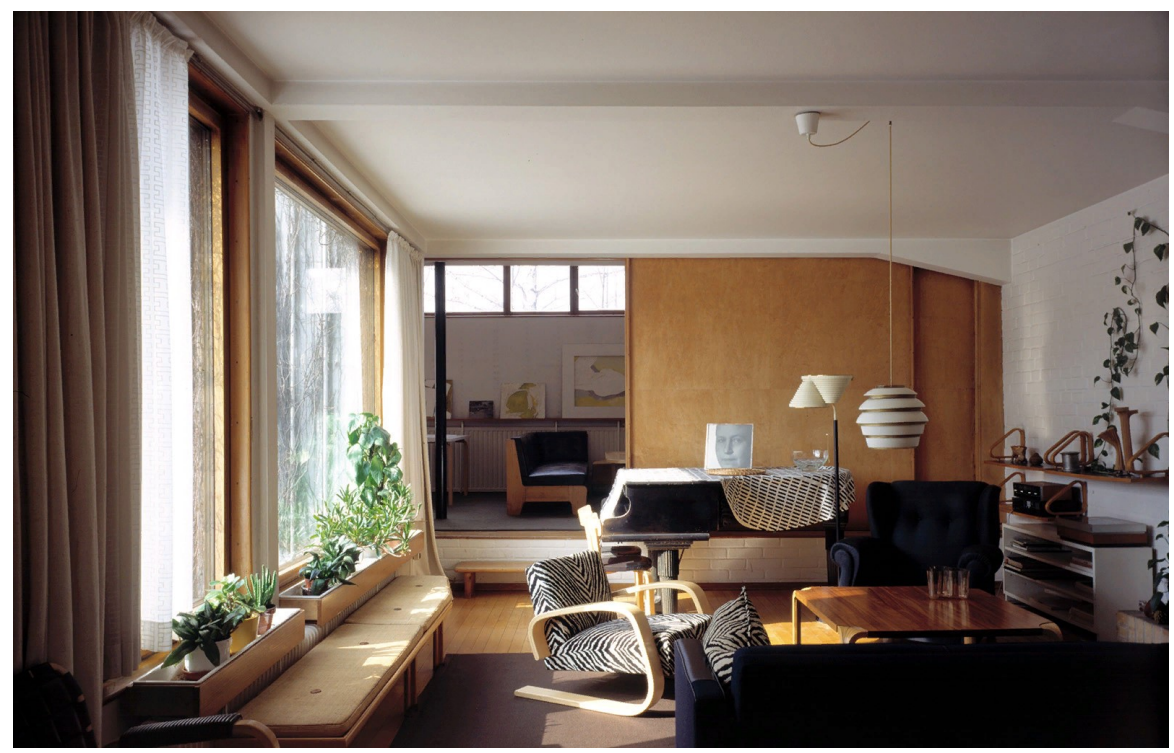

Figure 4: Finnish Dwelling

The designer transfers the vertical load on the seat of the chair into a spring-loaded "arkbutan" from the armrest. The chair in the interior of Aalto's house is very reminiscent of winter hunting skis with its springy wooden legs and base. According to the author Alvar Aalto - "In the creations of nature, forms arise from their internal construction" [7; p. 88]. With all the functionality and the lack of direct analogies with the national traditional crafts and art of Finland, there are Finnish national roots in his work. "In modern conditions, there is a need to preserve the local, original culture, which is on the verge of extinction due to the onslaught of modern technologies" [8; p. 76]. (Fig. 4)

Aalto was passionate about the idea of national romanticism. The beginning of his work coincides with the history of Finland gaining independence. According to our subjective opinion, there is also a designer's interest in gardening art and Japanese architecture in addition to the theme of Finland images.

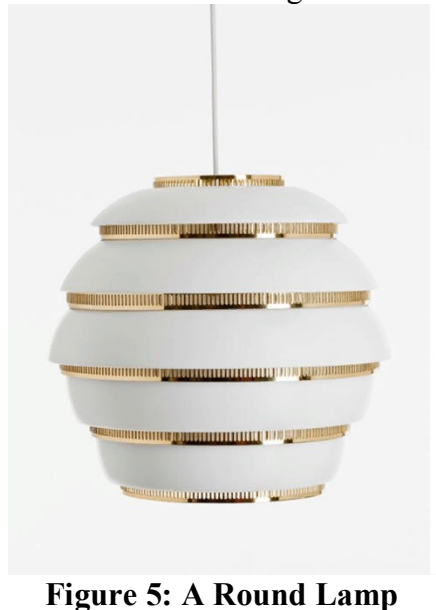

Figure 5: A Round Lamp

The elements of refraction in his work of traditional Japanese crafts are prompted in the semantics of the language of a round lamp - a chandelier developed by him. (Fig. 5) 


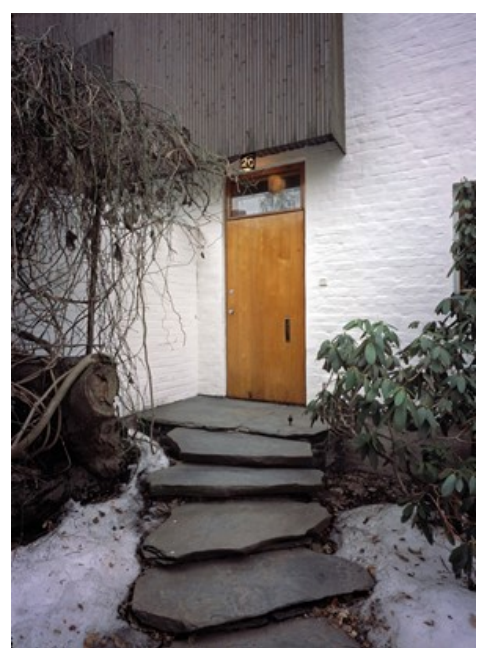

Figure 6 (a): Aalto House in Helsinki

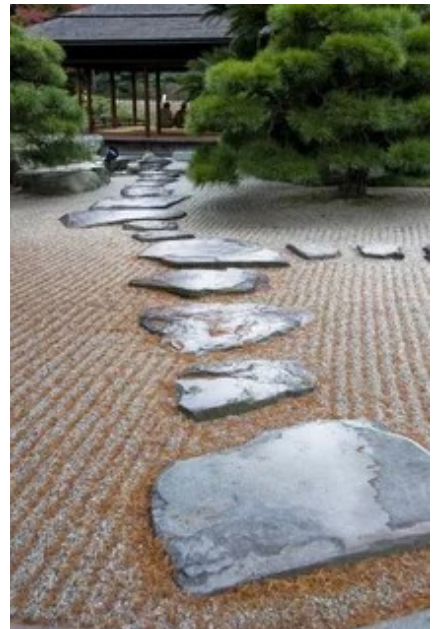

(b) Zen Japanese Garden

In addition to wood, the master used building materials: brick, granite, etc. "Every year new artificial materials appear in the industry. However, the material requires the test of time. Not all new materials are sufficiently studied, not all are "ripe" in order to use them for humans" [7; p.96]. This author's statement reflects his attitude to the materials used to create designs of various objects. So, in front of the door of the Aalto house in Helsinki, flat stones lie in the form of steps with the ends of the edges imitating the natural nature, unprocessed by human hands, corresponding to the images of Japanese garden paths, to Zen stone gardens. But this is not direct copying, which would be wrong from the standpoint of mixing different eras and cultures. Alvar Aalto broadcasts various associative images with his work. Another viewer will see European medieval castles in these steps of "unprocessed" slabs of stone. (Fig. 6)

The newly created artificial art form must meet the requirements of functionality, be constructively competently designed, from the standpoint of aesthetics, it must translate the values of architectural styles and the historical era in which the author of the project creates (the law of novelty and modernity).

In the preface to one of the first issues of the magazine "Journal of Design" (appeared in England in 1849) which has the word "design" in its title, the editor of the magazine Richard Redgrave noted: "Design has a dual nature. In the first place - strict compliance with the purpose of the created thing. The second is the decoration or ornamentation of this useful structure. For many, the word "design" is most often associated with the second, with an independent ornament contrasted with a useful function, rather than with the unity of both aspects" [9].

The artificial organism created by the designer is built according to the compositional (formal) laws of nature: for example, the rhythm of rain - the rhythm of lines and spots in design, etc. The famous Aalto armchair Paimio recalls the image of a winter birch with curved to the ground, weeping branches without leaves. The seat and backrest create an image of birch bark. The armrests and legs of a chair with a back and a seat [10] have something in common with their bends. (Fig. 7)

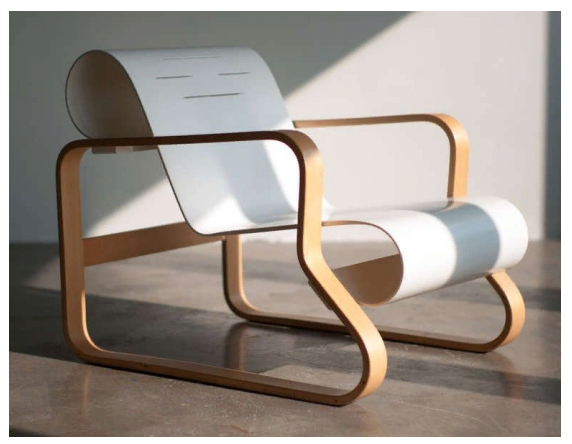

Figure 7: The Armchair Paimio, 1932

The prevalence of form over content is characteristic of international architecture and design. But Aalto's works have the warmth of wood and the human scale. Modern searches in the field of design with the maximum prevalence of form over content usually lead to the national component leveling, to some "depersonalization" of architecture and design products. But this does not apply to Alvar Aalto's works. His projects are recognizable and very characteristic of the Scandinavian trend in design. "Design is a cultural product, an instrument of cultural construction, and a factor actively shaping culture at the same time" [10]. 


\section{Summary}

The products that are the product of the creative work of the designer-master meet the following rules:

1. does not mix ready-made elements of pictorial language codes of various architectural eras;

2. shows a deep approach to a color "palette" selection for a project;

3. selects the materials used to create the product design;

4. increases the balance ratio in the compositional pair "form - content" in favor of form.

Thus, it is possible to introduce the concept of "formal method or compositional analysis" into the practice of educational and creative, design and evaluation activities in design. In pedagogical practice, another indicator of the evaluation criterion appears, represented by the practical implementation of the formal method in educational works.

\section{Conclusions}

Thus, we can conclude that a master, a student, a pupil must consciously make the choice of form and content ratio during a creative or educational product development. After this or that correlation in the balance "form - content", a new conditional language code is selected and a new artificial art form is created. In the end, there is the creation of a bright distinctive artistic image in the product design.

\section{Acknowledgements}

The work is performed according to the Russian Government Program of Competitive Growth of Kazan Federal University.

\section{References}

1. Vlasov V.G. New Encyclopedic Dictionary of Fine Arts: in 10 vol. V. 3. / V.G. Vlasov. 3rd ed., revised and added. St. Petersburg: ABC Classic. 2010. - 765 p.: Ill. (Series "Encyclopedias").

2. Valeeva R.A, Karkina S.V, Starcic A.I. Distance learning for aesthetic education - Informed professional development and life-long learning of student teachers//ACM International Conference Proceeding Series. - 2018. Vol., Is. - pp. 597-603.

3. Karkina S.V. Person-centered esthetic education of university students by means of integration of arts//The Social Sciences (Pakistan). 2015. V. 10. № 4. pp. 449-453.

4. Minervin G.B. Architectonics of industrial forms. - M., 1970. Issue. 1, p. 30.

5. Vazieva A., Valieva, R. Architectural Stimuli in the Perception of Urban Residents. // Culture and Art Research, 8(1). - 2019. - pp. 157-164.

6. Makhmutova Madina, Karamova Klara, Akhmetshina Gulnaz, Djuzbaeva Aizada. Decorative and applied art of tatar and kirghiz in the aspect of turkic people artistic culture study // Herald National Academy of Managerial Staff of Culture and Arts. № 3(2) - 2018., pp. 161-164.

7. Alto A. Architecture and humanism. Translated from Fin., English, French, German. Ed. by A. Gozak. - M.: Progress, 1978.- 219 p., Ill.

8. G. Akhmetshina, Z. Galeeva, R. Salakhova. Ways of development of decorativeapplied creativity in the contemporary world // X. Uluslararasi Türk sanati, tarihi ve folkloru kongresi /Sanat Etkinlikleri. - 2018. - pp.75-77

9. Heskett J. Industrial Design. - London, 1995. - p. 20.

10. Lavrentiev A.N. The history of design. - M.: Gardariki, 2007. - 303 p. - ISBN 5-8297-0262-2. 